\title{
Impact of environmental agents on non-woven polylactide/natural rubber agrofiber
}

\author{
Yulia Tertyshnaya ${ }^{1-3, *}$, Maksim Zakharov ${ }^{1}$, Alina Ivanitskikh², and Anatoliy Popov ${ }^{1,3}$ \\ ${ }^{1}$ Emanuel Institute of Biochemical Physics, Russian Academy of Sciences, 119334 Moscow, Russia \\ ${ }^{2}$ Federal Scientific Agroengineering Center VIM, 109428 Moscow, Russia \\ ${ }^{3}$ Plekhanov Russian University of Economics, 117997 Moscow, Russia
}

\begin{abstract}
In the work an eco-friendly non-woven fiber made of polylactide and natural rubber with a rubber content from 0 to $15 \mathrm{wt} . \%$ was obtained by electrospinning. The influence of distilled water and UV irradiation on the agrofibers has been investigated. The water sorption test showed that the addition of natural rubber into the polylactide matrix does not significantly affect the degree of water absorption of the fibrous materials, which is in the range of $49-50.6 \%$. Thermal characteristics after 180 days of degradation in distilled water at $22 \pm 2{ }^{\circ} \mathrm{C}$ and UV irradiation at a wavelength of $365 \mathrm{~nm}$ during 100 hours were determined using the differential scanning calorimetry. Changes in the values for glass transition and melting temperatures, and the degree of crystallinity were determined.
\end{abstract}

\section{Introduction}

Electrospun non-woven fibers have shown significant potential in a number of applications: chemical sensors, tissue engineering, seed mats, filtration systems. Electrospinning is one of the promising methods for obtaining nanometer- and micrometerscale fibers. The electrospinning is based on a combination of mechanical and electrostatic forces applied to a polymer solution or melt orientated in an electric field.

Polylactide (PLA) is polyester obtained from renewable raw materials. Lactic acid is released during fermentation of waste vegetable raw materials such as corn, beets, cereals. At the next stage, polylactide is obtained from lactic acid by polymerization [1-3]. Crystalline PLA has properties similar to those of known polymers, such as polypropylene and polyethylene, but PLA has advantages: biocompatibility and biodegradability [4-7]. Under the influence of environmental agents, PLA decomposes to carbon dioxide and water.

Natural rubber is a high-quality polymer derived from commercial latex, which is obtained from the milky juice of a rubber-bearing plant. It has received great attention in medical, industrial, and agricultural fields. Natural rubber has been shown to be biodegradable by various mold fungi and a wide range of bacteria [8]. The repeat unit is 1,4 -cis isoprene and the polymer is widely used for creating composite materials.

\footnotetext{
* Corresponding author: terj@rambler.ru
} 
PLA/NR non-woven eco-friendly fiber can be used in agricultural applications as the seed mats or a covering material. The current study is to investigate the influence of environmental factors such as water and UV irradiation on degradation of PLA/NR fiber.

\section{Materials and methods}

Polylactide $4032 \mathrm{D}$ with a molecular weight of $1.7 \times 10^{5} \mathrm{~g} / \mathrm{mol}$ and $\rho=1.24 \mathrm{~g} / \mathrm{cm}^{3}$ produced by Nature works (USA), as well as natural rubber SVR 3L from Vietnam Rubber Group (Vietnam) with poly(cis-1,4-isoprene) content of 91 - $96 \mathrm{wt} / \%$ was used.

The polymer solutions for electrospinning were prepared by dissolving PLA and $\mathrm{PLA} / \mathrm{NR}$ in the right ratio in chloroform. The mixtures were heated at $60{ }^{\circ} \mathrm{C}$ for about $4-5$ min. The polymer solution was placed in a syringe with a needle inner diameter $0.7 \mathrm{~mm}$, set up vertically. The electrospinning experiments were performed at room temperature $\left(20 \pm 2^{\circ} \mathrm{C}\right)$. The content of natural rubber in the mixture was $0,5,10$ and $15 \mathrm{wt} . \%$

The morphology of the samples was observed at different magnification using Olympus CX43 Polarization Optical Microscope (Japan) supplied digital camera FHDU2CMOS6 with the measurement function.

The kinetics of distilled water absorption by samples was studied for 240 hours after the materials reached equilibrium water absorption (GOST 4650-2014 (ISO 62: 2008)). Square samples with a side of $30 \mathrm{~mm}$ were used for testing. The test was performed for five samples of each composition. Before the test, the samples were dried at $(40 \pm 2)^{\circ} \mathrm{C}$ for $24 \mathrm{~h}$, and then cooled in a desiccator over a desiccant at $(22 \pm 2)^{\circ} \mathrm{C}$ and weighed no more than 5 minutes after removal from the desiccator. Further, the samples were placed in a vessel with distilled water taken in an amount of at least $8 \mathrm{~cm}^{3}$ per $1 \mathrm{~cm}^{2}$ of the sample surface. The test samples were not allowed to be in contact with each other, or the walls of the vessel, and were completely covered with water. The liquid was agitated by rotating the vessel at least once a day.

After an equilibrium amount of water in the sample was established, it was removed from the water, dried with a filter paper, and weighed using an electronic balance no more than 1 min later.

The degree of water absorption was calculated as (1):

$$
\mathrm{W}=\left(\left(\mathrm{m}_{2}-\mathrm{m}_{1}\right)\right) / \mathrm{m}_{1} \times 100 \%
$$

where $m_{1}$ - initial mass of the sample, $\mathrm{m}_{2}$ - mass of the sample after water influence.

The resistance to photodegradation of the pure PLA and PLA/NR samples was studied using the VL-6.LC ultraviolet radiation source from the company Viber Lourmat (France). The wavelength $(\lambda=365 \mathrm{~nm})$.

\section{Results and Discussion}

\subsection{Morphology}

In the work PLA/NR agrofiber of various compositions was obtained from the solution by electrospinning and their morphology was studied. PLA/NR fiber samples show bead string morphology with a mean fiber diameter of $6.58 \mu \mathrm{m}$ as shown in Fig. $1 b$. When the NR content is $15 \mathrm{wt}$ \%, the number of bead strings increases. 


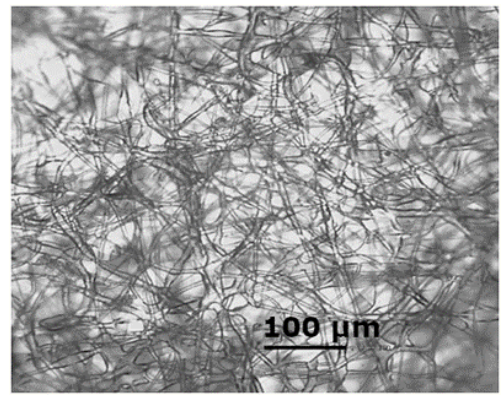

a

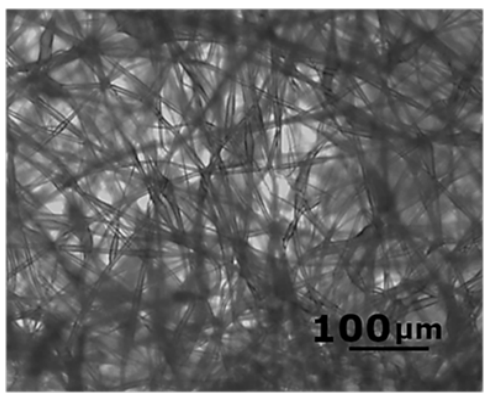

$\boldsymbol{b}$

Fig. 1. Microphotos of non-woven fiber 100\% PLA (a) and 90\% PLA/ 10\% NR (b). Magnification of 100 times.

\subsection{Water absorption}

The water absorption test allows to determine the equilibrium amount of water absorbed by the material under certain conditions. The water adsorption by polymers depends on many components. For example, the degree of crystallinity and temperature play an important role. The degree of water absorption is very dependent on the type of material. It is obvious that due to the porous structure, the fiber absorbs more water than the film. In this case, it is the type of material that plays the main role, and not the hydrophilicity or hydrophobicity of the polymers in the composite. It should be noted that the degree of water absorption of PLA (4043D) is about $2 \%$ but the PLA/NR fibrous materials absorbs much more water. The experiment showed that the addition of natural rubber has almost no effect on the degree of water absorption $W$ (Fig. 2).

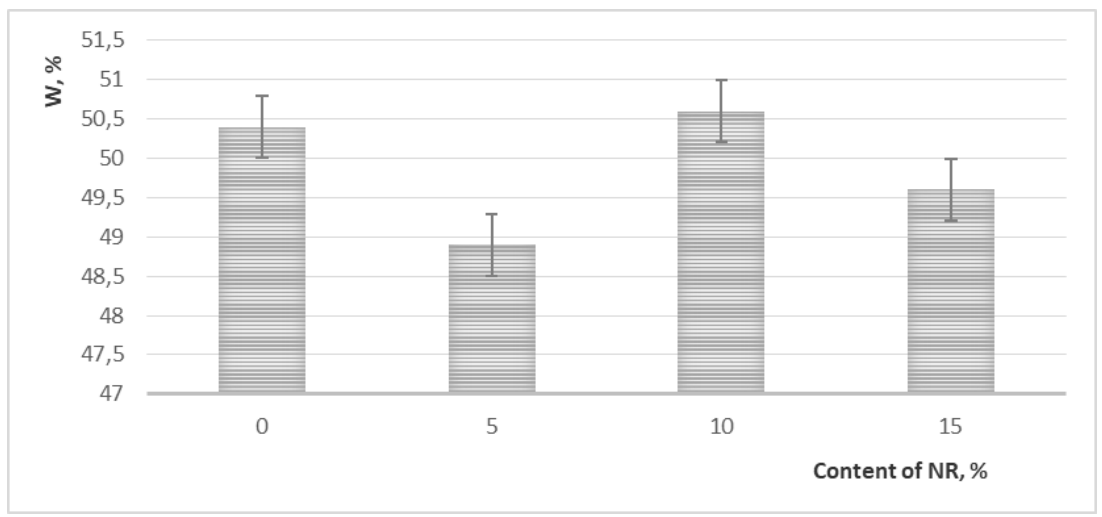

Fig. 2. Degree of water absorption ( $W, \%)$ of non-woven PLA/NR fiber containing 0, 5, 10 and 15 wt.\% of NR.

When studying the effect of water on non-woven fiber PLA/NR during 180 days, it was determined that after hydrolytic degradation on the melting thermograms, the melting temperature $\left(\mathrm{T}_{\mathrm{m}}\right)$ of PLA/NR samples changes insignificantly and the glass transition peak of PLA almost disappears. Such behavior of $T_{g}$ is attributable to a decrease in molecular weight [9]. An increase of the PLA degree of crystallinity is a consequence of the disintegration of the amorphous phase and a possible decrease in the molecular weight (Table 1). The remaining PLA chains then have higher mobility, and they can reorganize themselves more easily which leads to an increase of the degree of crystallinity. 
Table 1. DSC data of PLA/NR non-woven fiber samples: initial and after 180 days of water degradation.

\begin{tabular}{|c|c|c|c|c|c|c|}
\hline $\begin{array}{c}\text { NR } \\
\text { content, } \\
\text { wt\% }\end{array}$ & \multicolumn{3}{|c|}{ Initial samples } & \multicolumn{3}{c|}{ After degradation in water for 180 days } \\
\cline { 2 - 7 } & $\begin{array}{c}\mathrm{T}_{\mathrm{g}},{ }^{\circ} \mathrm{C} \\
\left(\Delta \pm 0.5^{\circ} \mathrm{C}\right)\end{array}$ & $\begin{array}{c}\mathrm{T}_{\mathrm{m}},{ }^{\circ} \mathrm{C} \\
\left(\Delta \pm 0.5^{\circ} \mathrm{C}\right)\end{array}$ & $\begin{array}{c}\chi_{\mathrm{cr}}, \% \\
(\Delta \pm 1 \%)\end{array}$ & $\begin{array}{c}\mathrm{T}_{\mathrm{g}},{ }^{\circ} \mathrm{C} \\
\left(\Delta \pm 0.5^{\circ} \mathrm{C}\right)\end{array}$ & $\begin{array}{c}\mathrm{T}_{\mathrm{m}},{ }^{\circ} \mathrm{C} \\
\left(\Delta \pm 0.5^{\circ} \mathrm{C}\right)\end{array}$ & $\begin{array}{c}\chi_{\mathrm{cr}}, \% \\
(\Delta \pm 1 \%)\end{array}$ \\
\hline 0 & 61.2 & 164.1 & 34 & -- & 168.3 & 46 \\
\hline 5 & 63.3 & 168.2 & 36 & -- & 167.1 & 46 \\
\hline 10 & 66.0 & 167.0 & 38 & -- & 167.0 & 47 \\
\hline 15 & 65.1 & 166.1 & 37 & -- & 166.2 & 47 \\
\hline
\end{tabular}

\subsection{Effect of UV irradiation}

It is well-known that UV irradiation is a strong aggressive environmental factor. During photo destructive processes, polymers and products made from them change various properties and colour and lose their performance characteristics. When studying the effect of UV radiation on polymer materials, irradiators with different wavelengths are used. Researchers often use ultraviolet sources with wavelengths 254, 312, $365 \mathrm{~nm}$.

It is important to determine the effect of NR on the photodegradation of non-woven fiber samples, and the addition of NR increases or decreases the resistance of non-woven fibers to UV radiation, which is very important for covering material used in open-ground conditions. The UV irradiation effect on fiber was determined by the DSC method. Figure 3 shows thermograms of the initial samples of PLA/NR fibers and after UV irradiation for 20, 50 and 100 hours.

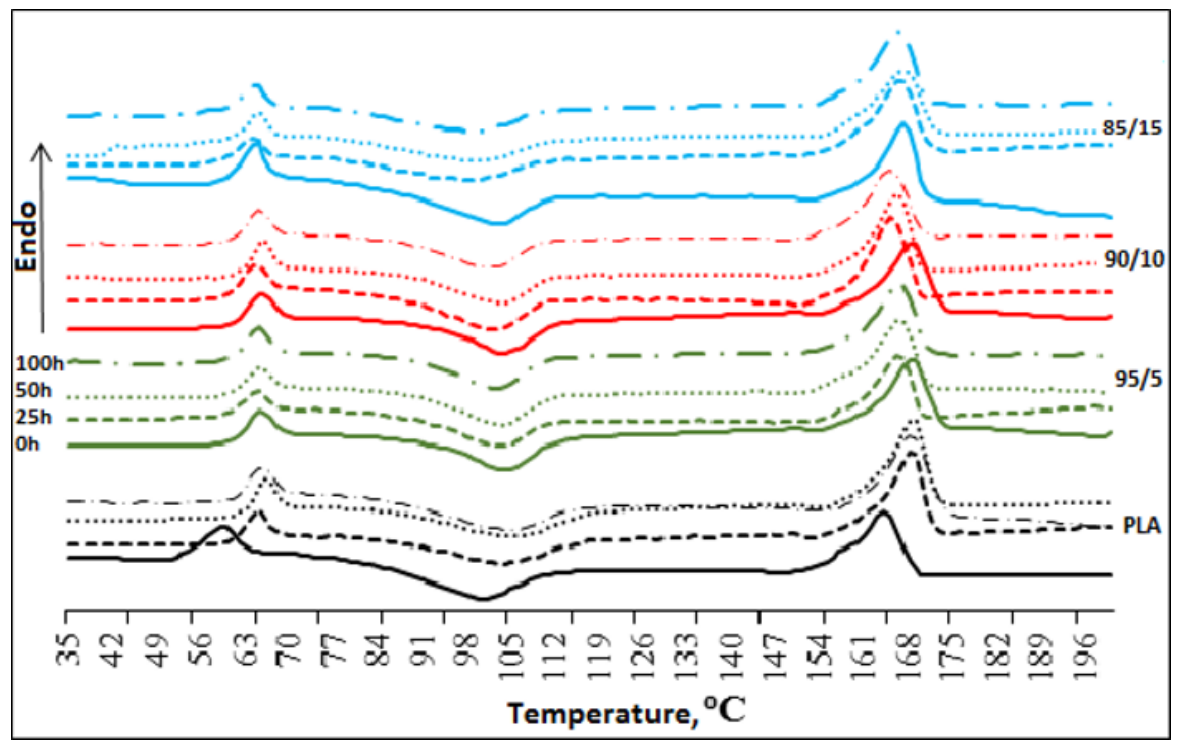

Fig. 3 DSC curves (initial and after UV degradation) of samples of non-woven PLA/NR fiber containing $0,5,10$ and $15 \mathrm{wt}$. \% of NR.

One can see from the DSC data that when exposed to UV radiation, the glass transition temperature $\left(\mathrm{T}_{\mathrm{g}}\right)$ of the PLA changes ambiguously. In pure PLA the $\mathrm{T}_{\mathrm{m}}$ increases by $6{ }^{\circ} \mathrm{C}$ and the degree of crystallinity increases by $7 \%$. In samples of non-woven fiber PLA/NR of the PLA $T_{g}$ changes slightly, the melting and crystallization temperature $\left(T_{c}\right)$ decreases by 2-3 ${ }^{\circ} \mathrm{C}$. The $\mathrm{T}_{\mathrm{g}}$ of pure PLA sample increases after 20 and 50 hours of the experiment. It is possible that the effect of UV irradiation $(\lambda=365 \mathrm{~nm})$ for $50 \mathrm{~h}$ causes an annealing effect, 
in which $\mathrm{T}_{\mathrm{g}}, \mathrm{T}_{\mathrm{m}}$ and the degree of crystallinity increase. Only after $100 \mathrm{~h}$ of photodegradation the PLA $T_{g}$ decreases, and in contrast to pure PLA, $T_{m}$ of PLA/NR samples decreases. It should be noted that with harder radiation $(\lambda=254 \mathrm{~nm})$, the melting temperature of PLA decreased to $135^{\circ} \mathrm{C}$ during 100 hours of exposure [10].

\section{Conclusions}

Biobased and eco-friendly non-woven PLA/NR fiber was obtained by electrospinning with a different content of NR (5 - 15 wt.\%). The addition of NR to the PLA matrix leads to a slight increase of the melting temperature and the degree of crystallinity of PLA. All samples of PLA/NR have the similar degree of water absorption. NR has no negative effect on the hydrolysis of PLA, which would be beneficial for the biodegradation of PLA modified by NR. Effect of UV irradiation $(\lambda=365 \mathrm{~nm})$ for $100 \mathrm{~h}$ leads to the changes in thermophysical characteristics: $\mathrm{T}_{\mathrm{m}}$ and $\mathrm{T}_{\mathrm{c}}$ of PLA/NR fiber samples decreases.

\section{References}

1. L.-T. Lim, R. Auras, M. Rubino, Prog. Polym. Sci, 33, 820 (2008)

2. D. J. Garlotta, Polym. Environ, 9, 63 (2001)

3. M.V. Podzorova, Y.V. Tertyshnaya, A.A. Popov, Rus. J. Phys. Chem. B., 8(5), 726 (2014)

4. V.K. Holm, S. Ndoni, J. Risbo, J. Food Sci. 71, 40 (2006)

5. V. Piemonte, F. Gironi, J. Polym. Environ, 21, 313 (2013)

6. Y.V. Tertyshnaya, A.A. Popov, Polym. Sci. Ser. D. 13 (3), 306 (2020)

7. Y.V. Tertyshnaya, N.S. Levina, A.A. Popov, M.N. Moskovskii, A.Yu. Izmailov, Fibre chemistry, 51(2), 117 (2019)

8. H. Tsuji, K. Suzuyoshi, Polym. Degrad Stab., 75, 347 (2002)

9. S.K. Saha, H.Tsuji, Polym. Degrad Stab., 91, 1665 (2006)

10. Y.V. Tertyshnaya, M.V. Podzorova, Rus. J. Phys. Chem. B., 14(1), 167 (2020) 